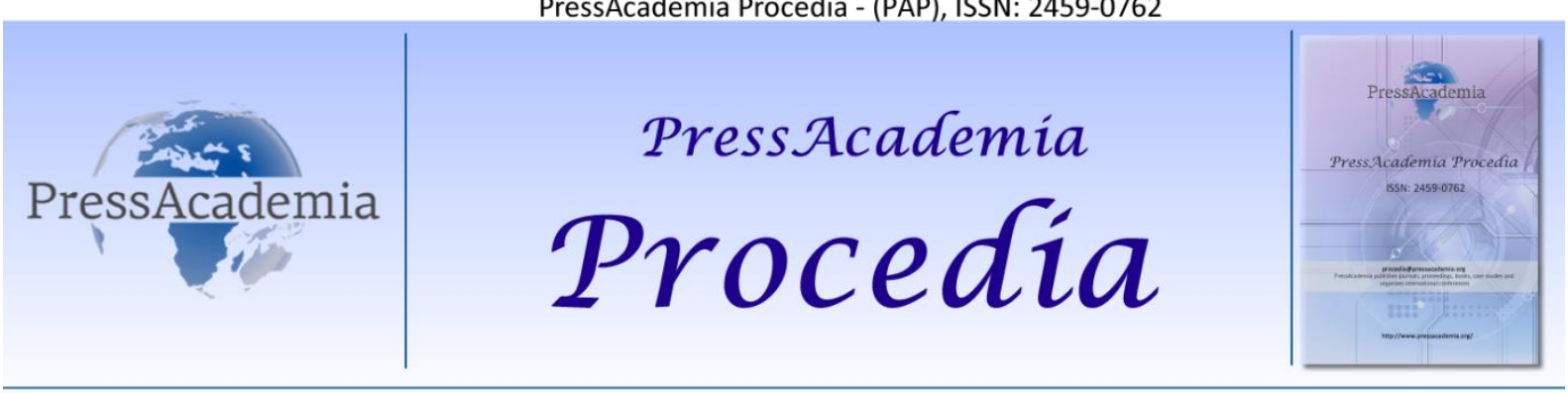

2nd World Conference on Technology, Innovation and Entrepreneurship

May 12-14, 2017, Istanbul, Turkey. Edited by Sefer Şener

\title{
INVESTIGATION OF THE EFFECTS OF RENEWABLE ENERGY SOURCES ON INTERCONNECTION NETWORKS
}

\author{
DOI: $10.17261 /$ Pressacademia.2017.618 \\ PAP-WCTIE-V.5-2017(56)-p.410-419
}

\author{
Mustafa Tekin ${ }^{1}$, O. Fatih Kececioglu ${ }^{2}$, Ceyhun Yildiz ${ }^{3}$, Ahmet Gani ${ }^{4}$, Hakan Acikgoz ${ }^{5}$, Mustafa Kesenek ${ }^{6}$ Mustafa Sekkeli $^{7}$ \\ ${ }^{1}$ Department of Electrical and Electronics Eng., Faculty of Eng. and Architecture, K.Maraş Sütçü Imam University. mustafatekin@ksu.edu.tr \\ ${ }^{2}$ Department of Electrical and Electronics Eng., Faculty of Eng. and Architecture, K.Maraş Sütçü İmam University. fkececioglu@ksu.edu.tr \\ ${ }^{3}$ Graduate School of Natural and Applied Sciences, K.Maraş Sütçü İmam University. cyildiz@ksu.edu.tr \\ ${ }^{4}$ Department of Electrical and Electronics Eng., Faculty of Eng. and Architecture, K.Maraş Sütçü İmam University. agani@ksu.edu.tr \\ ${ }^{5}$ Graduate School of Natural and Applied Sciences, Kilis 7 Aralık University. hakanacikgoz@ksu.edu.tr \\ ${ }^{6}$ TEDAŞ General Directorate, K.Maraş. kesenekksu@gmail.com \\ ${ }^{7}$ Department of Electrical and Electronics Eng., Faculty of Eng. and Architecture, K.Maraş Sütçü İmam University. msekkeli@ksu.edu.tr
}

\begin{abstract}
Demand for electricity is increasing due to population growth, the development of technology and the level of prosperity of communities. Coal, natural gas, oil, etc., which are called traditional sources can no longer meet this demand. In addition, these resources are harmful to the environment and have high costs. For all these reasons, the trend towards alternative energy sources is increasing. These sources are called renewable energy sources. Solar, wind, water, geothermal etc. as examples of renewable energy sources. In addition to producing enough energy, it is also necessary to use the produced energy efficiently. This is defined as the energy quality (power quality). The power quality parameters are defined to keep the obtained electric energy within certain limits in terms of quality. These parameters include; harmonic, voltage flicker, voltage deviation etc. Through this study; it has been analyzed, with the increasing number of solar power plants connecting to the network, what kind of changes occurred in the electricity network and how the solar power plants affect the network in terms of energy quality. The analysis was carried out by evaluating the one month data from a $5 \mathrm{MW}$ solar power plant.
\end{abstract}

Keywords: Renewable energy, solar power plant (SPP), power quality, harmonic, voltage deviation.

\section{INTRODUCTION}

With each passing day the development of technology and the increase of the human population increases the energy demand (electricity energy). Figure-1 shows this situation clearly in Turkey scale. When Figure-1 is examined; while the energy demand of Turkey is 40,000 MW in 2015, it is expected that this demand will be about 60,000 MW in 2024.(Tekin et al., 2016a)

Energy circles in the world are turning to alternative energy sources because traditional resources (petroleum, coal, natural gas, etc.) are both harmful to nature and depletion of reserves. Hydro, solar, wind, biomass and geothermal energy can be given as examples to these alternative sources and clean energy production sources.(Tekin et al., 2016a)

In addition to the production of electricity, it is also important to use the produced energy efficiently and in good quality; because the lack of quality of electricity affects both producers and consumers as well as the economy in the negative. The concept of power quality has been introduced to reduce these negatives the least and to determine the sources that affect the quality of electricity in a negative way more quickly.

Power quality is a set of constraints that allow devices to behave in the desired way without performance and lifetime losses. The poor quality of the energy can cause equipment such as microprocessors which are sensitive to current or voltage imbalance used in the industry and the equipment used by the consumer to be damaged.(Kocaman and Özdemir, 2009) Energy quality distortions classified as; current and voltage harmonics, voltage sags \& swells, flicker, neutral-toground potential difference, current and voltage imbalance between phases, frequency change, etc.(Şahin et al., 2014) 
Figure-1: Electricity Energy Demand Forecast of Turkey Between 2015-2024

(Türkiye Elektrik Enerjisi 5 Yıllık Üretim Kapasite Projeksiyonu, 2015)

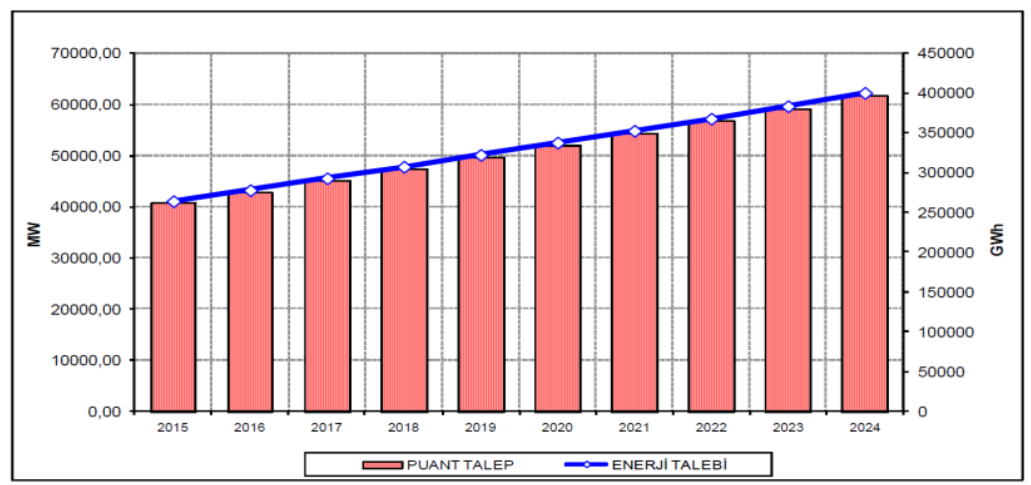

In order to avoid the above mentioned inconveniences, power quality parameters have been controlled all over the world by introducing restrictions by regulations. "Regulation on Procurement Duration, Commercial and Technical Qualities of Electricity Power Supplied in Electricity Market Distribution System" covers these limitations for Turkey.

Based on the importance of the above-mentioned issues, the 1-month electrical data from a 5 MW Solar Power Plant (SPP) was taken with the help of a power analyzer and from this data it was evaluated how this SPP influenced the network in terms of harmonics and voltage deviations.

\section{LITERATURE REVIEW}

Gabriel Tanasescu and colleagues (2016) investigated how a $5 \mathrm{MW}$ solar power plant affected the interconnection network in terms of flicker. In another study, Semih Hürmeydan et al. (2016) investigated how small-scale SPPs affect the network's in terms of power quality (harmonic and voltage imbalance) at low voltage levels. Pertti Pakonen et al. (2016) they evaluated the voltage flicker, total harmonic distortion and total demand distortion values by connecting a $6 \mathrm{~kW}$ SPP to the network. And they observed that flicker increased in cloudy weather. They also emphasized the need for good design of the inverter so that the SPP does not adversely affect the power quality. Amirullah et al. (2015) investigate how total harmonic distortion and total demand distortion are affected by the coupling of SPPs to the networks to which residential and industrial loads are separately connected. As a result, both values are understood to comply with IEEE standards. Carlos Gonzalez et al. (2012) investigate how overvoltage, undervoltage and voltage imbalance phenomena are affected by the connection of a feeder where residential loads are connected together with SPP at low voltage level. Minas Patsalides and colleagues (2012) have modeled the system to analyze harmonic variations by connecting the increasing number of SPP to the distribution network. And as a result of the study, they arrived at the conclusion that the SPPs did not pose a threat to the network and that the harmonics were within the limit values. Pedro A. B. Block et al. (2014), in their study; they evaluated how to change the power quality parameters by connecting a 1 MVA SPP to the network. And at the end of the study, increases in current harmonics were observed at sunrise and sunset.

In our study, actual measured values were taken from the point (medium voltage level=36,000), which is connected to a 5 MW large-scale SPP interconnection network. In the direction of datas; daily, weekly and monthly changes in power quality (harmonics and voltage deviations) caused by SPP during the winter months in the network were investigated.

\section{DATA AND METHODOLOGY}

\subsection{Power Quality Parameters}

\subsubsection{Harmonics}

Harmonics can be defined as all electrical signals originating from nonlinear loads or from unbalanced generators, except for network frequency $(50 \mathrm{~Hz})$. Harmonics $(3,5,7, \ldots)$, which are single times the main frequency, are called odd harmonics, and which are double times the main frequency $(2,4,6 \ldots)$ are called even harmonics. Harmonics which smaller than $50 \mathrm{~Hz}$ are called subharmonics, and which is not a complete rigid of $50 \mathrm{~Hz}$ are called interharmonics (for example, $170 \mathrm{~Hz}$ ).(Tekin et al., 2016b)

Harmonics are one of the most important of energy quality parameters. Due to the economic effects of harmonics and the ability to adversely affect network operation, power systems must be monitored in detail.(Şahin et al., 2014)

Harmonics do not only distort the waveforms, but also they can lead to overheating of transformers and conductors; deterioration of di-electric materials such as cables and capacitors, heavy damage, reduced efficiency, reduced economic 
periods of use; increased losses in power lines; communication systems near the power lines may be adversely affected, overheating in electric machines, noisy operation and mechanical oscillations.(Keçecioğlu et al., 2015) Harmonic contamination can often be carried over the electricity distribution system and affect neighboring facilities in the same system.(Şahin et al., 2014)

The most important parameter defined for harmonic distortion is Total Harmonic Distortion (THD). THD is an indication of an impairment in an electrical signal. The boundary values of this variable are specified in IEEE 519-2014 standards. THD formula for voltage is given in Equation-1.(Tekin et al., 2016b)

$T H B_{V}=\frac{\sqrt{\sum_{i=2}^{40} V_{i}}}{V_{1}} \times 100 \quad($ EPDK, 2016)

The boundary values of voltage harmonics in the IEEE 519-2014 standard are shown in Table-1.

Table 1: Boundary Values for Voltage Harmonics (IEEE 519-2014 Standard, 2014)

\begin{tabular}{|c|c|c|}
\hline $\begin{array}{l}\text { Barrier Voltage at Common } \\
\text { Port } \\
\text { (V) }\end{array}$ & $\begin{array}{l}\text { Odd } \\
\text { Harmonic } \\
(\%)\end{array}$ & $\begin{array}{l}\text { Total Harmonic } \\
\text { Distortion THD } \\
(\%)\end{array}$ \\
\hline $\mathrm{V} \leq 1 \mathrm{kV}$ & 5 & 8 \\
\hline $1 \mathrm{kV}<\mathrm{V} \leq 69 \mathrm{kV}$ & 3 & 5 \\
\hline $69 \mathrm{kV}<\mathrm{V} \leq 161 \mathrm{kV}$ & 1.5 & 2.5 \\
\hline $161 \mathrm{kV}<\mathrm{V}$ & 1 & $1.5^{*}$ \\
\hline \multicolumn{3}{|c|}{$\begin{array}{l}\text { High-voltage systems can have up to } 2.0 \% \text { THD where the cause is a } \\
\text { HVDC terminal whose effects will have attenuated at points in th } \\
\text { network where future users may be connected. }\end{array}$} \\
\hline
\end{tabular}

\subsubsection{Voltage Deviation $(\Delta \mathrm{V})$}

The voltage deviation is that the network voltage goes below or exceeds the rated voltage. The limit value defined for voltage deviation in Turkey is $\pm 10 \%$. $95 \%$ for a week of values taken from the system should remain in this limit. It is the responsibility of the distribution company to keep the mains voltage at these values. There can be many reasons for voltage deviation; but this study focuses on the effects of grid-connected SPP on this parameter.

In Turkey, the limit values for the voltage deviation allowed to be formed in the network by connecting a SPP to the network are given in table-2. According to the table-2, the threshold allowed when connecting and disconnecting SPP is \pm 3\%.(Şimsek and Bizkevelci, 2015)

Table 2: Voltage Deviation Boundary Values Applied in Turkey (Şimsek and Bizkevelci, 2015)

\begin{tabular}{|l|c|}
\hline & Limit Values \\
\hline SPP Connecting & \pm 3.3 \\
\hline SPP Disconnecting & \pm 3.3 \\
\hline
\end{tabular}

The SPP raises the mains voltage when connecting to the network, and reduces the mains voltage when disconnecting from the network. Therefore, the point at which SPP connects to the network is important, and this connection point needs to be chosen according to the worst cases. For this reason, the analysis of the feeders to which SPP is connected should be done with great care.

\section{FINDINGS AND DISCUSSIONS}

\subsection{Harmonic Measurements}

In this part of the study, the data which received from the $5 \mathrm{MW}$ SPP that was connected to the network at medium voltage level, between the 01.01.2017 and 31.01.2017 were evaluated. Evaluation was made in terms of voltage harmonics and voltage deviations. One-day, one-week and one-month graphs of harmonics and voltage deviations were created. Thus how the SPP that was connected to the interconnected network, influences the network in terms of voltage deviations and harmonics has been examined. In the study, the harmonics values except for 3, 5, 7th were not considered because they were very small. 


\subsubsection{Daily Harmonic Measurements}

Figure-3-(a, b, c, d). a) 3rd Harmonic, b) 5th Harmonic, c) 7th Harmonic, d) THD Figures

The figures in this section of the study were obtained from the SPP's datas that were taken at 10 minute intervals on 16.01.2017. Figure 2, which shows the load flow in the network, is provided to help evaluate the harmonic distortions. When Figure- 2 is examined, it is observed that the system current falls to the lowest value $(600 \mathrm{~A})$ when time is between 12:00-13:00. It is also clear that consumption increased after 17:00.

\section{Figure 2: Network Load Graph}

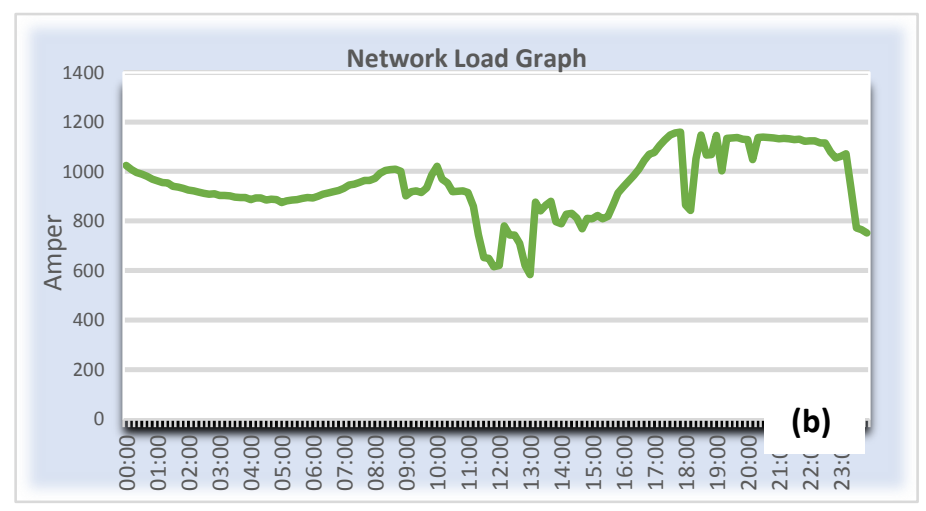

3, 5, 7th harmonics and THB values are seen in Figure-3-(a, b, c, d) respectively. According to these graphs; it is seen that the 3 rd harmonic during the day does not exceed the limit value of $3 \%$ for medium voltage level. It is understood that the 3rd harmonic reaches its maximum value at noon hours while it is at the lowest values at night hours. It is thought that SPP causes this harmonic to reach its maximum value at noon. Because SPP is producing the most intensive energy at that time.

It is seen that from the figüre-3-b, 5th harmonic generally exceed the limit value (3\%) throughout the day. It is observed that 5 th harmonic drops below the limit (3\%) between 08:00 and 13:30. The reason of this situation is evident from figure-2 (network load graph). That is, the hours that the 5th harmonic falls below the limit value are the hours when the load is minimum. So that the load current reduction causes the decrease in the 5 th harmonic.

It is seen that the 7th harmonic is observed at small values as 0,5\% at the times when SPP is not in operation (18:00-07:00) and reaching $2 \%$ at the times when SPP is active during the day, but the limit value is not passed.

When the figure of THD is examined, it is observed that it changes between $3 \%$ and $4 \%$ in general during the day. Since the 5th harmonic is dominant in the system, there is a decrease in THD between 08:00-13:30 as in the 5th harmonic. However, THD has not exceeded the limit of $5 \%$ for medium voltage.

(a)

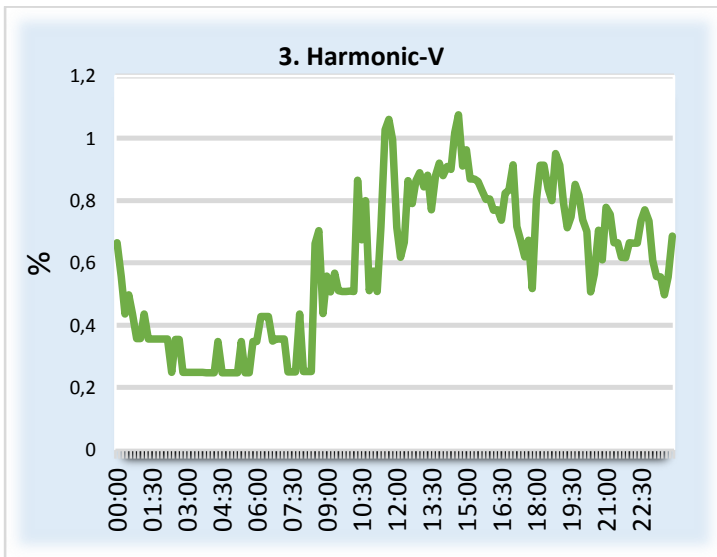

(c)

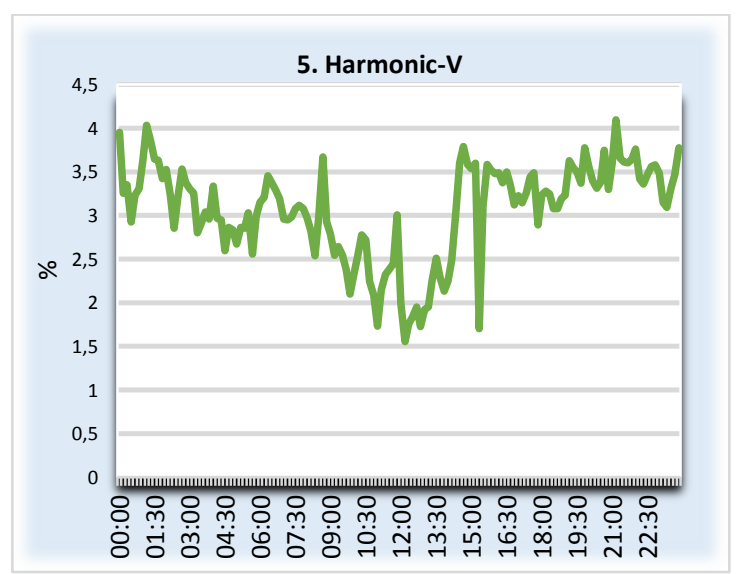

(d) 

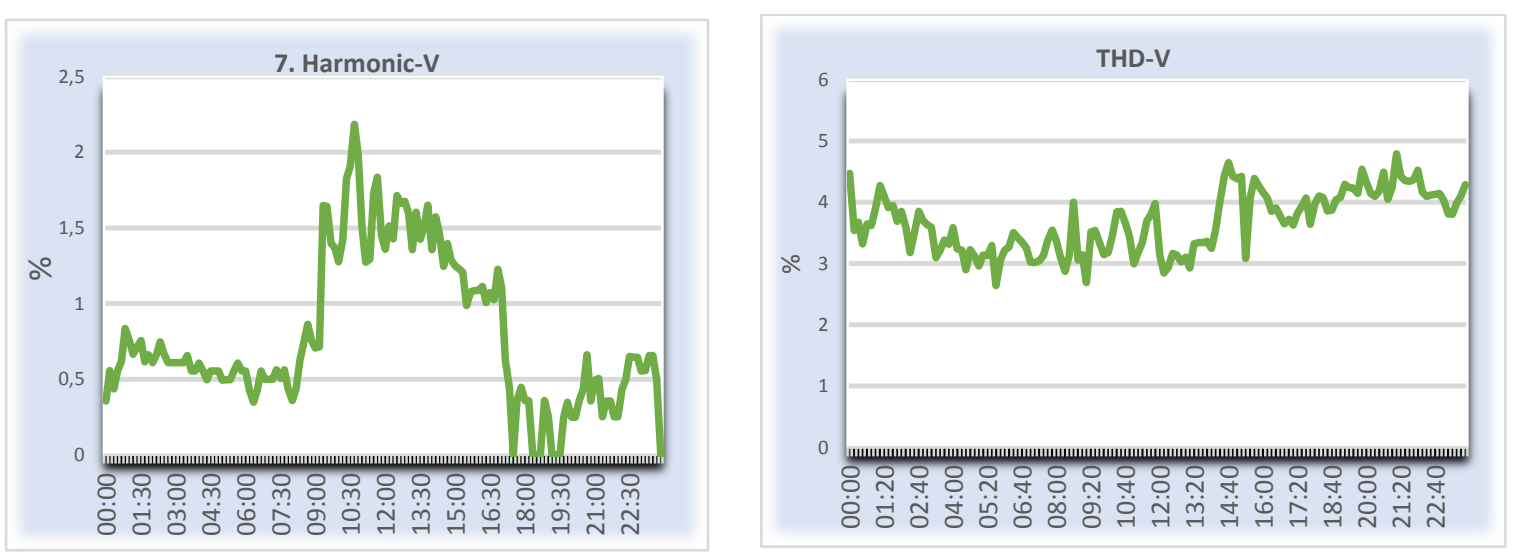

\subsubsection{Weekly Harmonic Measurements}

In this part of the article, the graphs, obtained from the weekly data which were received from the network on 01.01.2017 -

Figure-4-(a, b, c, d). a) 3rd Harmonic, b) 5th Harmonic, c) 7th Harmonic, d) THD Figures

07.01.2017, were evaluated. 3, 5, 7th harmonics and THD values are seen in figure-4-(a, b, c, d) respectively.

When looking at figüre-4-a; 3. harmonic varies from $0,5 \%$ to $1 \%$ in general, except for some sudden ups and downs. 3rd harmonic therefore provides standards for weekly measurements. As in the case of one-day measurements, it can be seen from the graph that the 3rd harmonic tends to increase at the times when SPP is in operation (07:30 - 18:00) in a weekly measurements.

When the 5th harmonic graph is examined for one week measurements; the 5th harmonic has exceeded limit values for medium voltage (3\%), many times. As in the case of one-day measurements, it is understood that the 5 th harmonic tends to decrease at times when the network current decreases. It is understood that the 5th harmonic does not comply with the standard that is $95 \%$ of the weekly measurements should not exceed the limit value. On some days it seems that the 5 th harmonic reached as $8 \%, 7 \%$.

When one week's 7th harmonic graph is examined; it is understood that, as in the 3rd harmonic, the 7th harmonic is also increasing at the times when SPP is active. However, it appears that the 7 th harmonic has never exceeded the $3 \%$ limit value that is defined in the standards. It is observed that the 7 th harmonic reaches a maximum value of $2.5 \%$ within one week period.

When a weekly figure of THD is considered; it is seemed that, in parallel with the 5th harmonic, the THD has also exceeded the limit value (5\%).

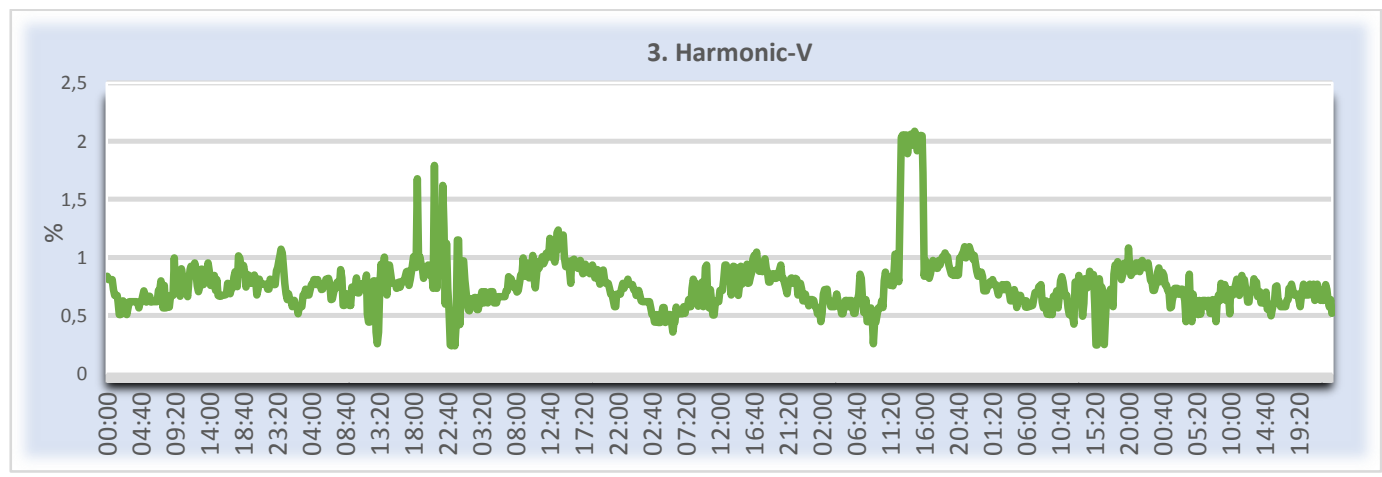



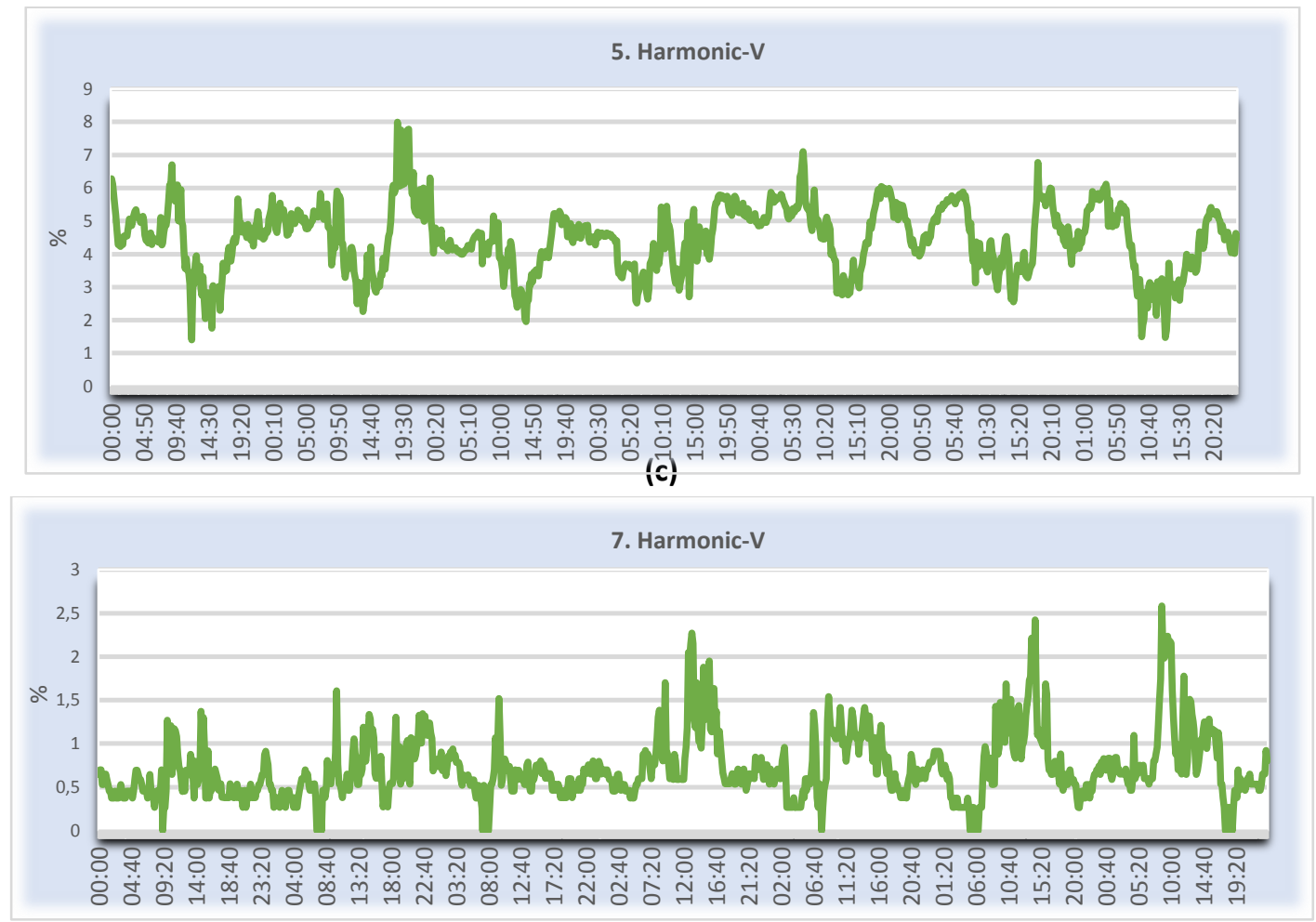

(d)

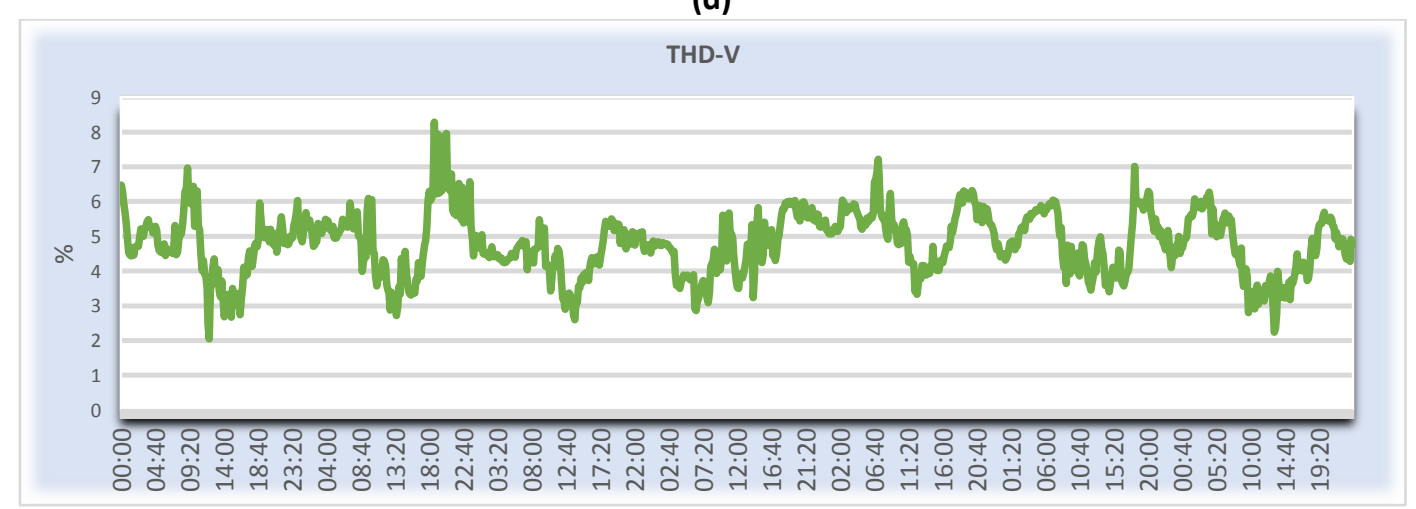

\subsubsection{Monthly Harmonic Measurements}

In this section of the article, the graphs, obtained from the monthly data which were received from the network on 01.01.2017-31.01.2017, were evaluated. 3, 5, 7th harmonics and THD values are seen in figure-5-(a, b, c, d) respectively.

Figure-5-(a, b, c, d). a) 3rd Harmonic, b) 5th Harmonic, c) 7th Harmonic, d) THD Figures

From the area graph for the 3rd harmonic; it is understood that the 3rd harmonic has passed the border value only 2 times for 30 days. It is observed that the 3rd harmonic is generally around $1 \%$ for a month but sometimes it is about $2 \%$.

It is seemed that the 5 th harmonic is generally observed at $5 \%$ level. In this case, it is observed that the standard value of the 5th harmonics (3\%) has passed. From the 7th harmonic graph; it is understood that this harmonic is generally below $1 \%$, but in some days it has increased to $2 \%$ and very rarely exceeded the limit value of $3 \%$. But since these limitations crossings are too short, it does not affect the compliance of the 7th harmonic with the standards. Looking at the THD's one month graph; it is observed that this parameter is generally above $5 \%$, even on some days it has risen up to a value of $13 \%, 23 \%$ for a very short period of time. This shows that THD does not comply with the standards. 


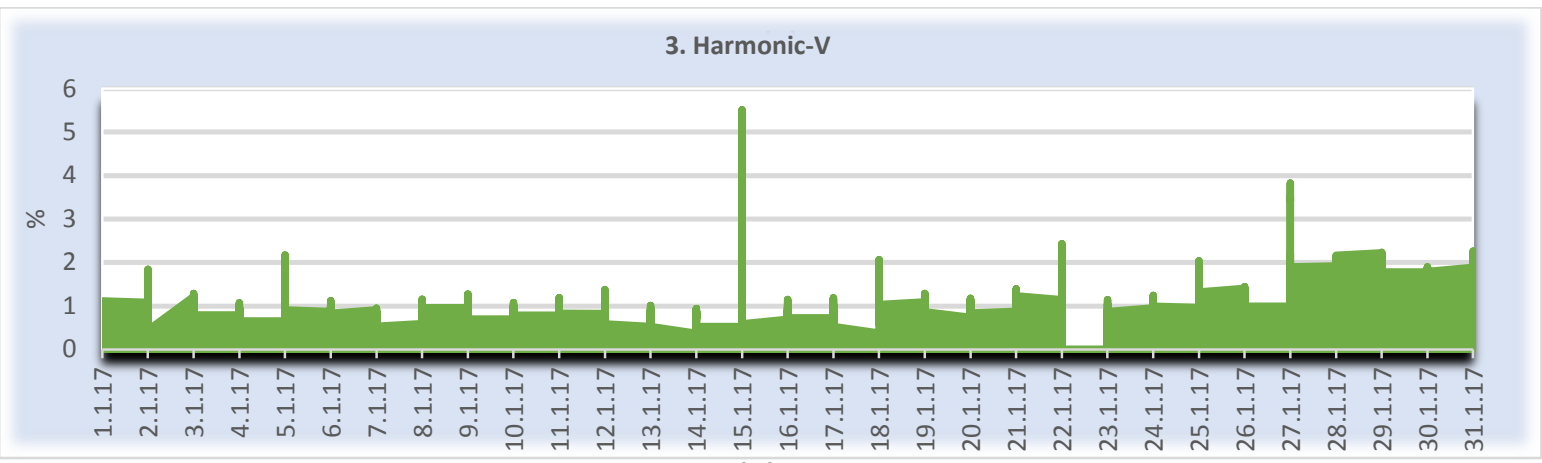

(b)

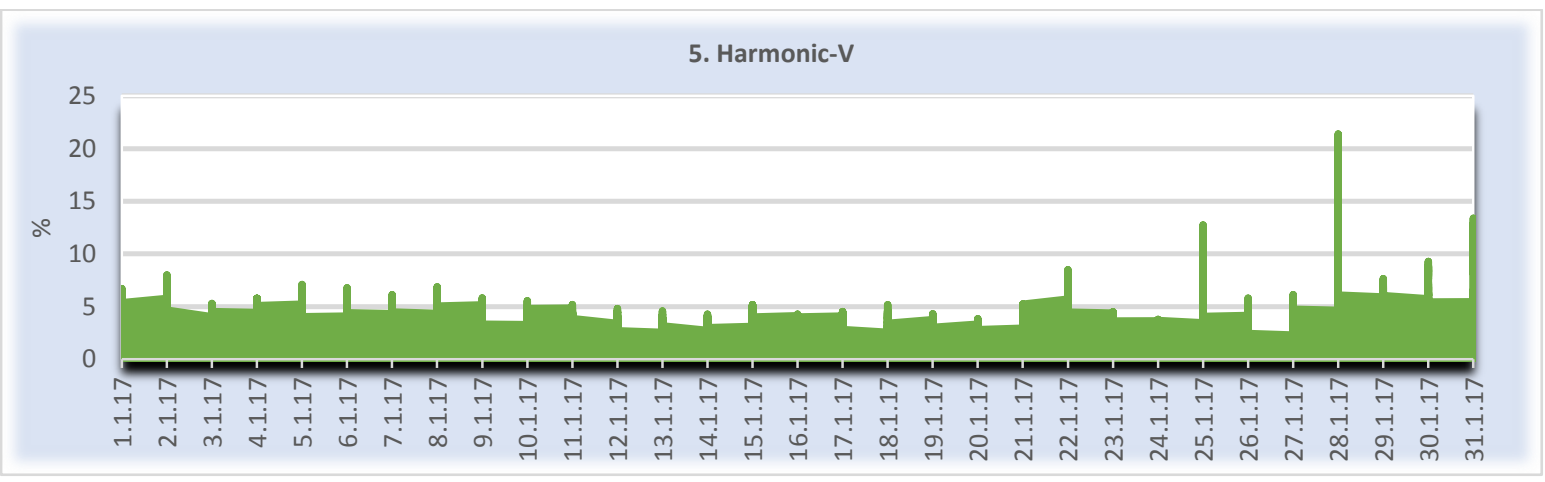

(c)

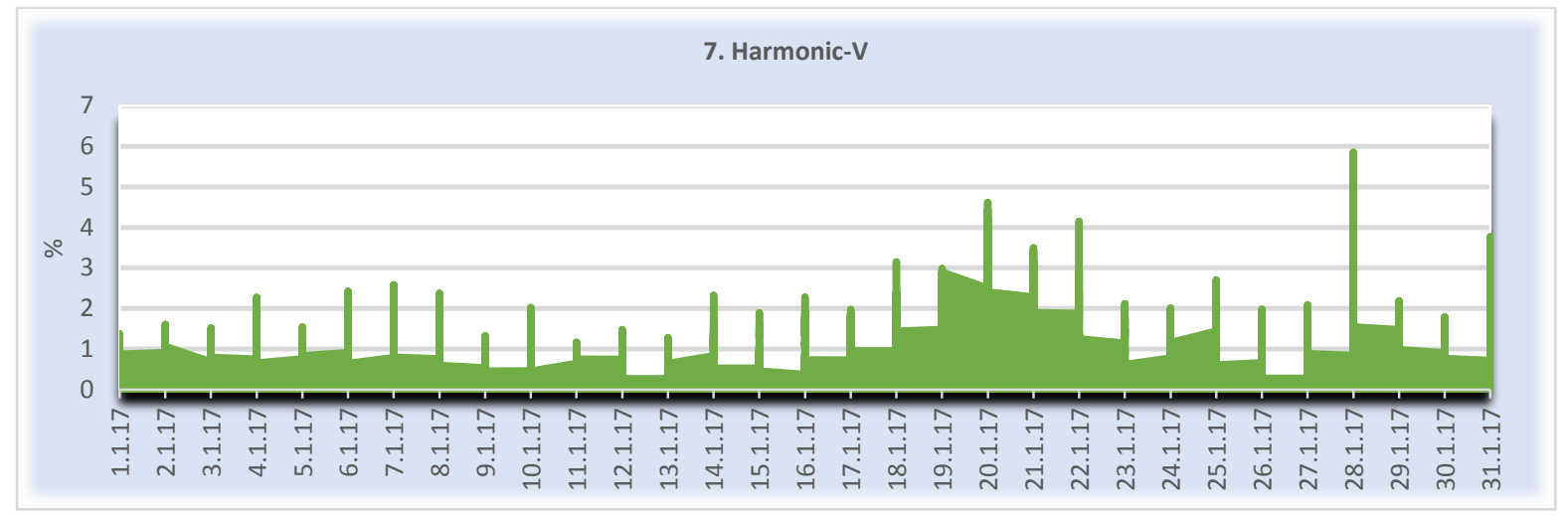

(d)

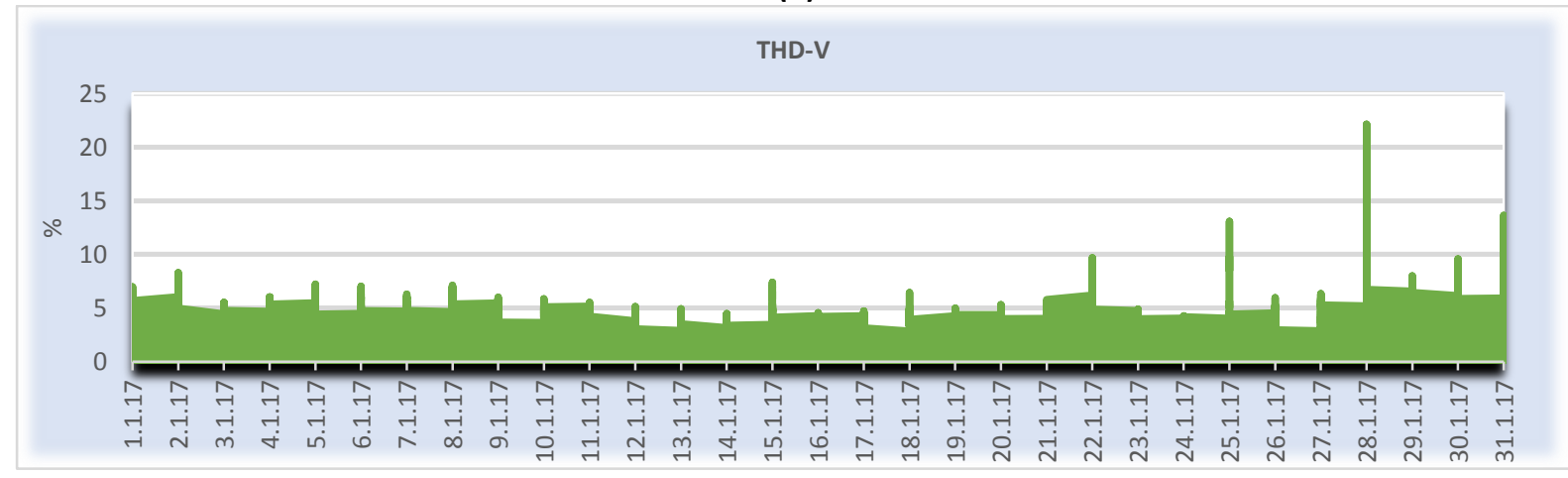


Figure-6-(a, b, c). a) Daily Voltage Deviation, b) Weekly Voltage Deviation, c) Monthly Voltage Deviation

\subsection{Voltage Deviation Measurements}

In this part of article figure-6-(a, b, c); which is three separate graphs obtained from one day, one week and one month measurements, is examined to see the deviations over the grid voltage.

From a daily chart; it is understood that a $1 \%$ change in system voltage is caused when the SPP enters and exits the circuit. Therefore, it is seen that the SPP has not exceeded the allowable $3 \%$ change in the system and stayed at the limit values, and it is understood that the network does not exceed the $10 \%$ deviation which is the limit value for the network. Looking at the weekly and monthly graphs; it is observed that the system voltage is below the limit value (10\%) except for shortterm voltage drop.

(a)
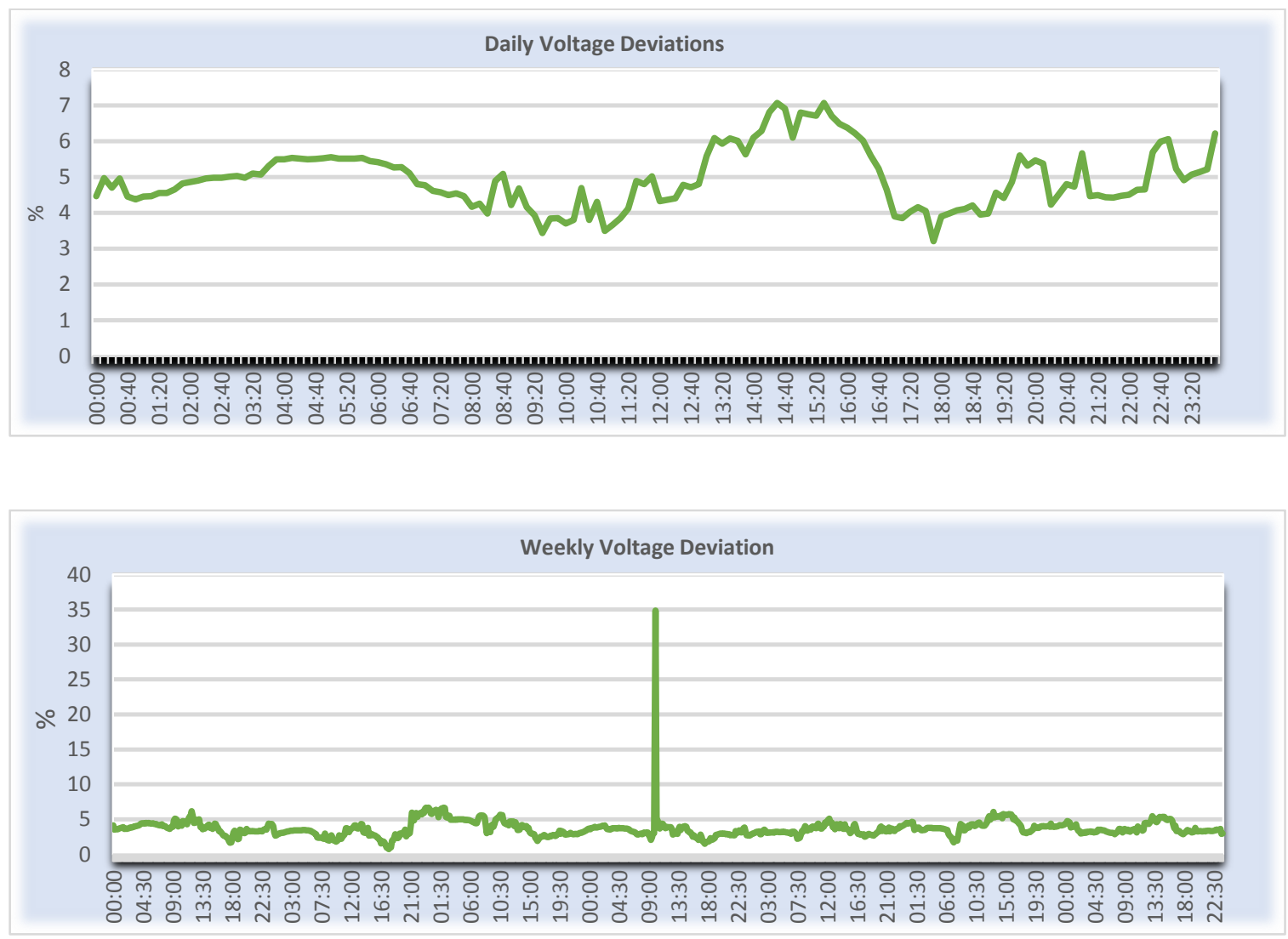

(c)

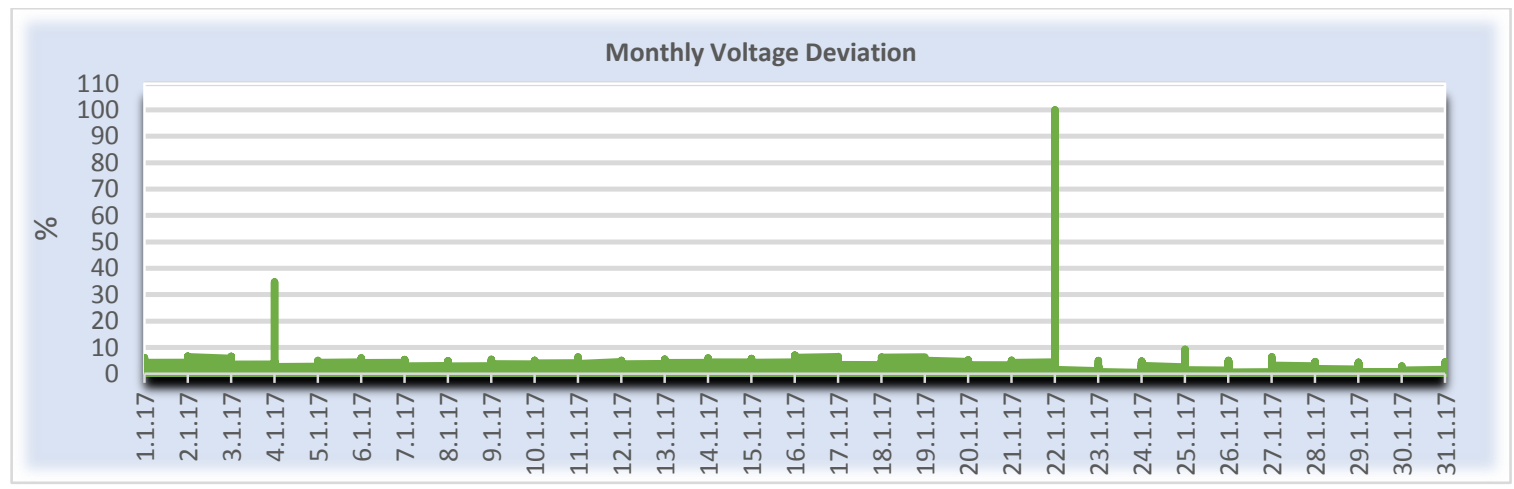




\section{CONCLUSIONS}

In this study, it was investigated how the $5 \mathrm{MW}$ SPP which was connected to the interconnected system from the medium voltage level, affects network's harmonics and voltage deviations. Within the scope of the research, electrical data were obtained from the place, where SPP was connected to the network, between 01.01.2017-31.01.2017. One day, one week and one month of harmonics and voltage deviations graphs were generated from these data. With interpretation of these graphs yielded the following results:

$>$ As a result of examining the daily graphs; it has been understood that the 3rd and 7th harmonics are in accordance with the limit values in the standard throughout the day. It is seen that the 3rd and 7th harmonics show their maximum values during the daytime hours (when SPP is active) while at the lowest values during night time. The 5th harmonic generally exceed the threshold value; but it was found to be the lowest value between 08:00 and 13:30, when the load on the system decreased. It has been observed that THD is below the limit of $5 \%$ during the day.

$>$ As a result of reviewing the weekly figures; it is understood that 3rd and 7th harmonics are appropriate for the weekly limit values defined in the standards. 3rd and 7th harmonics showed the highest values during the daytime hours of weekday (when SPP was active). It has been observed that the 5th harmonic generally exceed the limit values in the week and do not comply with the standards. THD's, in parallel with the 5th harmonic, limit values generally exceeded during the week.

$>$ It is understood that monthly graphs show parallel results with weekly graphs.

$>$ It is observed that the network voltage deviation is within the limits defined in the standard. SPP deviates the network voltage by $1 \%$ when entering and exiting the circuit; but remains within the standards ( $3 \%)$.

$>$ In the end of the work; SPP is effective on 3rd and 7th harmonics; but it is understood that these harmonics do not affect enough to cause the limit values to be exceeded. The analyzed network does not comply with the standards in terms of 5th harmonic and THD so active filtration method should be applied this network. In terms of voltage deviation, it was the result of providing the network and SPP were coply with the standards.

\section{REFERENCES}

A. Hill, C., Such, M. C., Chen, D., Gonzalez, J., Grady, W. M., "Battery Energy Storage For Enabling Integration Of Distributed Solar Power Generation", IEEE Transactions On Smart Grid, vol.3, no.2, 2012.

Akkoyunlu, A. (2006), "Türkiye'de Enerji Kaynakları ve Çevreye Etkileri”.

Amirullah, Penangsang, O., Soeprijanto, A. (2015), "Effect of Installation of Photovoltaic (PV) Generation to Power Quality in Industrial and Residential Customers Distribution Network", International Seminar on Intelligent Technology and Its Applications, p.p. 193-200.

Baggini, A. (2008), “Handbook of Power Quality”, Wiley, p.p. 151-155.

Bhattacharyya, S., Myrzik, J. M., Kling, W. L. (2007), “Consequences Of Poor Power Quality- An Overview”, UPEC, p.p. 651-656.

Block, P. A. B., Salamanca, H. L. L., Teixeira, M. D., Dahlke, D. D., Shiono, O. M., Donadon, A. R., Camargo, J. C. (2014), “Power Quality Analyses of a Large Scale Photovoltaic System", 5th International Renewable Energy Congress (IREC), p.p. 1-6.

"Elektrik Piyasasında Dağıtım Sisteminde Sunulan Elektrik Enerjisi Tedarik Sürekliliği, Ticari ve Teknik Kalitesi Hakkındaki Yönetmelik" (2016), Enerji Piyasası Düzenleme Kurumu (EPDK).

Enslin, J. H. R., Heskes, P. J. M. (2004), “Harmonic Interaction Between A Large Number Of Distributed Power Inverters And The Distribution Network", IEEE Transactions On Power Electronics, Vol. 19, No. 6.

Gonzalez, C., Geuns, J., Weckx, S., Wijnhoven, T., Vingerhoets, P., Rybel, T. D., Driesen, J. (2012), "LV Distribution Network Feeders in Belgium and Power Quality Issues due to Increasing PV Penetration Levels", 3rd IEEE PES Innovative Smart Grid Technologies Europe (ISGT Europe), p.p. 1-8.

Hürmeydan, S., Rosin, A., Vinnal, T. (2016), "Effects of PV Microgeneration on Rural LV Network Voltage Quality - Harmonics and Unbalance", Electric Power Quality and Supply Reliability (PQ), p.p. 97-100.

IEEE 519-2014 Standard. (2014), "IEEE Recommended Practice and Requirements for Harmonic Control in Electric Power Systems", IEEE Power and Energy Society.

Kandemir, Ç., Bayrak, M. (2015), "Fotovoltaik Sistemler Şebekeye Bağlı Olduğunda Oluşan Sorunlar”, VI. Enerji Verimliliği, Kalitesi Sempozyumu Ve Sergisi Bildirileri (EVK).

Keçecioğlu, Ö. F., Tekin, M., Gani, A., Sarı, M., Şekkeli, M. (2015), “Endüstriyel Isı Santrallerinde Enerji Kalitesi Ölçümü Ve Değerlendirilmesi, Kahramanmaraş Sütçü İmam Üniversitesi Örneği”, VI. Enerji Verimliliği, Kalitesi Sempozyumu Ve Sergisi Bildirileri.

Kocaman, Ç., Özdemir, M. (2009), "Güç Sistemlerinde Olușan Güç Kalitesi Bozunumlarının Çarpıklık Ve Basıklık Katsayıları İle Belirlenmesi”, 17th Signal Processing and Communications Applications Conference, IEEE, p.p. 341-344. 
Pakonen, P., Hilden, A., Suntio, T., Verho, P. (2016), “Grid-Connected PV Power Plant Induced Power Quality Problems -Experimental Evidence", 18th European Conference on Power Electronics and Applications (EPE'16 ECCE Europe), p.p. 1-10.

Patsalides, M., Georghiou, G. E., Stavrou, A., Efthimiou, V. (2012), “Assessing the Power Quality Behaviour of High Photovoltaic (PV) Penetration Levels inside the Distribution Network", 3rd IEEE International Symposium on Power Electronics for Distributed Generation Systems (PEDG), p.p. 709-716.

Şahin, M., Oğuz, Y., Tuğcu, H. Z. (2014) “Güç Sistemlerinde Enerji Kalitesini Etkileyen Harmoniklerin İncelenmesi”, EÜFBED - Fen Bilimleri Enstitüsü Dergisi Cilt-Sayı: 7-2, 199-218.

Şimşek, B., Bizkevelci, E. (2015), "Türkiye Elektrik Dağıtım Şebekesinde Fotovoltaik Sistemlerin Güç Kalitesine Etkisi”, IV. Elektrik Tesisat Ulusal Kongre Ve Sergisi Bildirileri.

Tanasescu, G., Busoi, S., Gorgan, B., Notingher, P. V. (2016), “Photovoltaic Power Plants Contribution To The Flicker Level In The Medium Voltage Energy Network. Case Study", Conference On Diagnostics In Electrical Engineering (Diagnostika), IEEE, p.p. 1-4.

Tekin, M., Sarı, M., Keçecioğlu, Ö.F., Gani, A., Açıkgöz, H., Yıldız, C., Şekkeli, M. (2016), “Power Quality Analysis Of A Campus Field: Case Study For Avşar Campus of Kahramanmaraş Sütçü İmam University", 4th International Symposium on Innovative Technologies in Engineering and Science, (ISITES2016) Alanya/Antalya, Turkey, 3-5 November.

Tekin, M., Keçecioğlu, Ö.F., Gani, A., Açıkgöz, H., Yıldız, C., Şekkeli, M. (2016), "The Role Of Kahramanmaraş In Turkey From The Standpoint Of Based On Traditional And Renewable Electricity Generation”, 10th International Clean Energy Symposium (UTES), 24-26 October, Istanbul, Turkey.

“Türkiye Elektrik Enerjisi 5 Yıllık Üretim Kapasite Projeksiyonu (2015 - 2019)”, 2015.

Yanıktepe, B., Özalp, C., Savrun, M. M., Köroğlu, T., Cebeci, Ç. (2011), “Rüzgar-Güneş Hibrid Güç Sistemi Osmaniye Korkut Ata Üniversitesi Uygulama Örneği”, 6th International Advanced Technologies Symposium (IATS'11), Elazığ, Turkey. 